\title{
Internet access for disabled people: Understanding socio-relational factors in Europe
}

\author{
Frederike Scholz ${ }^{1}$, Betul Yalcin², \& Mark Priestley ${ }^{2}$ \\ ${ }^{1}$ Work and Employment Relations Division, University of Leeds, Leeds, UK \\ ${ }^{2}$ School of Sociology and Social Policy, University of Leeds, Leeds, UK
}

\begin{abstract}
Access to the Internet has become a sine qua non-of everyday life. It also offers new routes to economic and social inclusion for disabled people. Research on the digital divide shows that social factors affect Internet access but disability status is often overlooked. This paper assesses the extent to which disability makes a difference and how it interacts with other social effects to produce distinctive forms of digital exclusion. The analysis uses survey data from 27 European countries to explore and model, statistically, the interactions between Internet access, disability status, age, gender, education, household financial situation and household composition. Multilevel analysis confirms that socio-demographic factors can explain much variance in outcomes but there is a distinctive disability effect. In particular, the adverse effects of financial constraint, aging and living alone are exacerbated among disabled people. New policies to strengthen e-accessibility, arising from the United Nations Convention on the Rights of Persons with Disabilities and from the European Union, are important but cannot ignore those who are still excluded from the online revolution. Disabled people are over-represented in this group. The evidence suggests that both accessible technologies and appropriate supportive relationships are needed to address this.
\end{abstract}

Keywords: ICT; Internet access; disabled people; digital divide; citizenship rights; Europe; EU; e-accessibility

\section{Introduction}

Information and communication technologies (ICTs), particularly the Internet, have transformed the way we live and communicate, in both private and public spheres of everyday life (Bakardjieva 2005; Wellman \& Haythornthwaite, 2008). They have evolved new ways of interacting in diverse contexts, from workplaces (Greenfield \& Davis, 2002) to higher education (Wall \& Sarver, 2003), offering new options for locational flexibility. Internet usage also impacts on 'psychological well-being, the formation and maintenance of personal relationships, group memberships and social identity...' (Bargh \& McKenna 2004, p. 573). These developments and impacts create both opportunities for, and barriers to, the full participation and equality of disabled people in society. From a social model perspective (Oliver, 1990), disability arises from unequal social relations between disabled and non-disabled people in disabling environments. As the Internet becomes increasingly ubiquitous in the landscapes of everyday life so enabling online environments, and equal access to them, must be viewed as intrinsic to achieving disability equality (Disability Rights Commission, 2004; Easton, 2013).

The concept of the 'digital divide' is well established (OECD, 2001), referring initially to gaps in access to ICTs and particularly to Internet access (Norris, 2001). With exponential growth in basic access, including mobile phone access, focus turned towards differential patterns of usage and skills (Cullen, 2003; Hargittai, 2001; Ragnedda \& 
Muschert, 2013; Sevron, 2002; Van Deursen \& Van Dijk, 2014; Warschauer, 2004) yet the underlying access divide deepens and intensifies for some social groups, including some groups of disabled people (Vincent \& Lopez, 2010).

Despite advances in Internet technologies, stronger non-discrimination legislation and a widening knowledge of web accessibility standards, much of the Internet remains inaccessible for many disabled people (Adam \& Kreps, 2009; Easton, 2013; EC, 2008; Goggin and Newell, 2003; Vincente \& Lopez, 2010). Policy attention to this disability dimension has intensified, notably in EU policy, but as a category for analysis disability has been often overlooked, or conflated within more generalised discourses of disadvantage groups (Adam \& Kreps, 2009; Pilling, Barrett, \& Floyd, 2004). Research interest in disability and digital exclusion has been growing (Adam \& Kreps, 2009; Cullen, 2003; Disability Rights Commission, 2004; Easton, 2013; Vincente \& Lopez, 2010). However, recent findings suggest that Internet adoption among disabled people in the USA still lags far behind population norms even after controlling for relevant socio-demographic variables (Dobransky \& Hargittai, 2016). There is a lack of evidence though to establish and untangle the interplay of such factors in Europe. This paper first addresses that challenge by examining the effect of disability status on access to the Internet, in interaction with other socio-economic variables in 27 EU Member States. These factors include age, gender, education, household financial situation and household composition. This confirms the extent of the disability equality gap and adds a new twist to existing explanations, focused on income and skills, by highlighting the digitally enabling potential of social relationships too.

\section{E-exclusion and Disability in the EU}

The proportion of EU households with Internet access from home was estimated at around 85\% in 2016, with broadband connection the most common form of access (Eurostat, 2016a). More than two thirds of Europeans use the Internet every day but still $14 \%$ have never used the Internet and patterns of access vary considerably between different EU countries and age groups (Eurostat, 2016a). These most recent key findings are based on Eurostat's major thematic 'Survey on ICT usage in households and by individuals' but disability status was not included as a variable and cannot be disaggregated for analysis. Based on data from the 2012 European Health and Social Integration Survey (EHSIS) Eurostat estimated that more than 73 million people in 27 EU Member States faced disabling barriers in one or more areas of life. More than half of them are over the age of 65 (Eurostat, 2016b) and this number is set to rise. Among them an estimated 3.4 million reported barriers to using the Internet, although the data was not sufficiently reliable to draw more detailed conclusions. In this context, it is important to consider that the risks of 'digital exclusion' threaten to compound existing forms of marginalisation and equality gaps between advantaged and disadvantaged groups, including between disabled and non-disabled people. In order to propose concrete steps towards closing equality gaps we must first make the extent and nature of those gaps visible.

Digital literacy and Internet access are widely recognised by the EU institutions as important for the enjoyment of citizenship rights, access to education, employment and political participation and the Digital Agenda for Europe is one of the flagships of EU strategy. Improving access and accessibility for disabled has emerged as a specific concern. Preparatory studies suggested that despite the adoption of international Web Accessibility Initiatives (WAI) guidelines for public websites and universal design for e-Accessibility, only five per cent of public websites appeared to fully comply by 2007 (EC, 2007). Further study indicated a lack of progress and pointed out a variety of problems, such as inconsistent attention to, or implementation of, e-Accessibility by industry (EC, 2008). In its 2008 Communication Towards an Accessible Information Society the European Commission acknowledged that EU law and policy had not delivered on e-accessibility and that the development of an inclusive information society had become a priority. Policy focus was directed to address inconsistencies across the European single market (for example, in highlighting the importance of accessible terminals for 'end-to-end connectivity' and rights to 'equivalent access' for disabled users in the Better Regulation and User Rights Directives of the updated Telecoms Package in 2009).

Policy commitment was strengthened by the EU's accession to the United Nations Convention on the Rights of Persons with Disabilities (UNCRPD) and inclusion of Accessibility as a priority theme in the launch of the European Disability Strategy 2010-2020 (EC, 2010). In 2015, after further market studies, the Commission published proposals for a long-awaited 'European Accessibility Act' (a Directive on accessibility requirements for 
products and services). In 2016 a new European Electronic Communications Code was proposed, which acknowledges access for disabled users explicitly and in relation to the UNCRPD. A new Directive was also adopted in 2016 to regulate web accessibility standards across the public sector. Clearly, there has been much progress in EU law and policy to make Internet technologies more accessible for disabled people - assuming they are equally able to access the Internet in the first place.

While limited accessibility has been identified as one factor that hinders disabled people's to access the Internet it is not the only one, and attention is inevitably drawn towards the disproportionate intersections of disability status with other socio-demographic factors that are well known to impact on Internet access. Most notable among these in the European context are age and level of formal education, with those aged over 55 or with lower level qualifications the least likely to be regular internet users (Eurostat 2016a). Disability prevalence is also much higher among older people and among persons with low qualifications compared to the average. These factors have implications for gender equality and for financial situation too - older disabled people are more likely to be women and a strong association between disability and poverty persists throughout the life course (Grammenos, 2015). In addition, it is relevant to consider that the availability of support from others in the household, or living alone, could have a sizeable effect on a person's Internet access (and disabled people may be disproportionately likely to live alone).

Vincente and Lopez (2010) adopted a multidimensional approach to disability and the digital divide using a dataset from the 2005 eUser project, funded by the European Commission in support the development of public online services. They found that, among those who reported limitations in activities 'only 35 percent used the Internet, as compared with 61 percent among those without impairments' (p. 51). However, this data covered only ten European countries and Internet usage increased rapidly after 2005. Their analysis suggested that affordability explained much of the disability gap but 'while socioeconomic factors play a role in the lower levels of use of the Internet, they do not explain the discrepancies on their own' (p. 59). Building on this approach, and that of Dobransky and Hargittai (2016) in the USA, we examine a much larger data set covering 27 EU countries. We use this data to identify the determinants of digital exclusion among disabled people and to isolate the factors that are most significant in facilitating or inhibiting regular Internet access at home. As far as we are aware, this is also the first international comparative analysis of individual-level and country-level factors concerning disability and digital exclusion.

The research questions can then be understood as follows: Can Internet use be significantly predicted by respondents' disability status? How do other individual level factors significantly influence Internet access? How do these factors influence the relationship between disability status and Internet access?

\section{Method}

\section{Data and Measurement}

We adopted an inferential statistical approach to explore and to model the extent to which disability status predicts patterns of Internet access and in interaction with other characteristics. The data was obtained from the Eurobarometer Opinion Survey Series 2012 (European Commission and European Parliament 2012). This series has been conducted on behalf of the European Commission since the 1970s and covers a wide range of topics. Following EU rules, it complies with the ethical and statistical principles of relevant national, EU and international legislation.

Eurobarometer 77.4 included a topic on 'Discrimination' (including disability discrimination) and a parallel topic (on Roma) included questions on possession of an Internet connection and Internet use at home, work and school. We were thus able to utilise the identification of disabled persons in interaction with items on Internet use, and other socio-demographic variables. The data was collected in June 2012 using a Proportionate Stratified Multistage Sample of personal interviews with EU nationals who were resident in EU Member States and aged 15 and over (i.e. it excludes non-EU nationals and non-residents). A total of 26,622 respondents were included with country sample sizes varying from 315 to 1,059 (responses from 1,056 respondents were removed at the later stage of multilevel analysis due to missing values). These data were processed and analysed using STATA v13. 
As a proxy for disability status, and in line with Eurostat and other research studies, we used the self-declaration of difficulty in carrying out daily activities due to long-term illnesses or disability. The wording is not ideal from a social model of disability perspective, as it suggests direct causality between a health condition and limitation of activities (which might be due to disabling barriers). In the context of discrimination, the survey asked also whether a respondent considered himself or herself to be part of 'A minority in terms of disability' (this more political definition yields a smaller group). As indicative of 'disability' in the social model sense we are interested in the extent to which any persons declaring impairments experience unequal social outcomes, compared to other persons, whether or not they identify with the minority identity.

Internet access was the dependent variable (using a dummy variable of 0 for not having access). In light of the existing research we then considered the following individual level socio-demographic factors: Gender, Age Cohort, Educational Attainment Level, Household Financial Situation and Household Composition. These were treated as categorical variables in the equation (recoded into dummy variables). Country of Residence was used as the unit of analysis for national comparisons. First, exploratory data analysis was conducted to investigate respondent characteristics for each of the above variables.

Chi-squared tests were used to test associations between each independent variable and the chances of having Internet access at home. This was followed by multilevel analysis (multilevel logistic regression) to understand more about the effect of different socio-demographic factors. This type of analysis shows whether simultaneously presented factors, in various combinations, have a statistically significant effect. It also quantifies the likelihood of different outcomes for different subdivisions of the sample (e.g. for women and men, or for different age groups). The analysis is carried out in steps (introducing each socio-demographic factor into the equation to explore its effect on Internet access when other factors are controlled). Finally, the interaction effects of other socio-demographic factors with disability status are investigated. This allows for the relative effect of the different factors to be modelled as they interact.

In view of the literature, Internet access at home is expected to differentiate as a function of subdivisions in the sample. We hypothesize that disability makes a statistically significant difference when all the other sociodemographic factors are controlled (null hypothesis that there is no significant effect). In a complex social environment, and aware of the findings of previous research, a combination of factors is more likely to predict Internet access at home than disability alone, so we seek to draw our conclusions from multilevel logistic regression rather than bivariate analysis.

\section{Results}

\section{Determinants of Digital Exclusion}

As concluded from the literature, Internet use differentiates as a function of socio-demographic factors and leaves some sub-groups in society at greater risk of digital exclusion than others. This is an exploratory study in the case of disability, which aims to disentangle its interrelationship with other known factors and point towards future lines of investigation. The findings confirm first that disability status (self-declared activity limitation) was a significant factor in differentiating Internet access in European countries. The subsequent sections then address the role of age, gender, educational attainment, financial situation and household composition.

Figure 1 indicates the digital divide between people with and without impairments in the EU member states (identified by their ISO-3166-2 two-letter Country Code). This shows that in every one of the 27 countries a smaller proportion of disabled people than non-disabled people declared Internet access at home in 2012. Overall, $70 \%$ of respondents said that they had Internet access at home. Around $17.5 \%$ declared a disability status and, among them, the rate of Internet access averaged just 52.2\% - indicating a headline disability equality gap of more than 20 percentage points (compared to a rate of $73.6 \%$ for non-disabled people).

The highest levels of access, and the narrowest disability gaps, were in Sweden (SE), Denmark (DK) and the Netherland (NL), with the lowest levels of access, and relatively wide gaps, in Greece (EL), Portugal (PT) and Romania (RO). Countries with generally high levels of Internet access at home did not always show high levels among disabled people (e.g. in Finland). This might be accounted for, in part, by variations in the prevalence of 
self-reported disability status, and population age profiles, but it suggests also the likelihood that different levels of social exclusion for disabled people exist in otherwise similar countries (which might arise from other social or policy factors, such as educational inclusion or poverty risk, for example). Nevertheless, we can conclude already that disability status is associated with lower than average levels of basic Internet access across all the European countries (as anticipated from Eurostat's inconclusive statistics and from previous research in the USA).

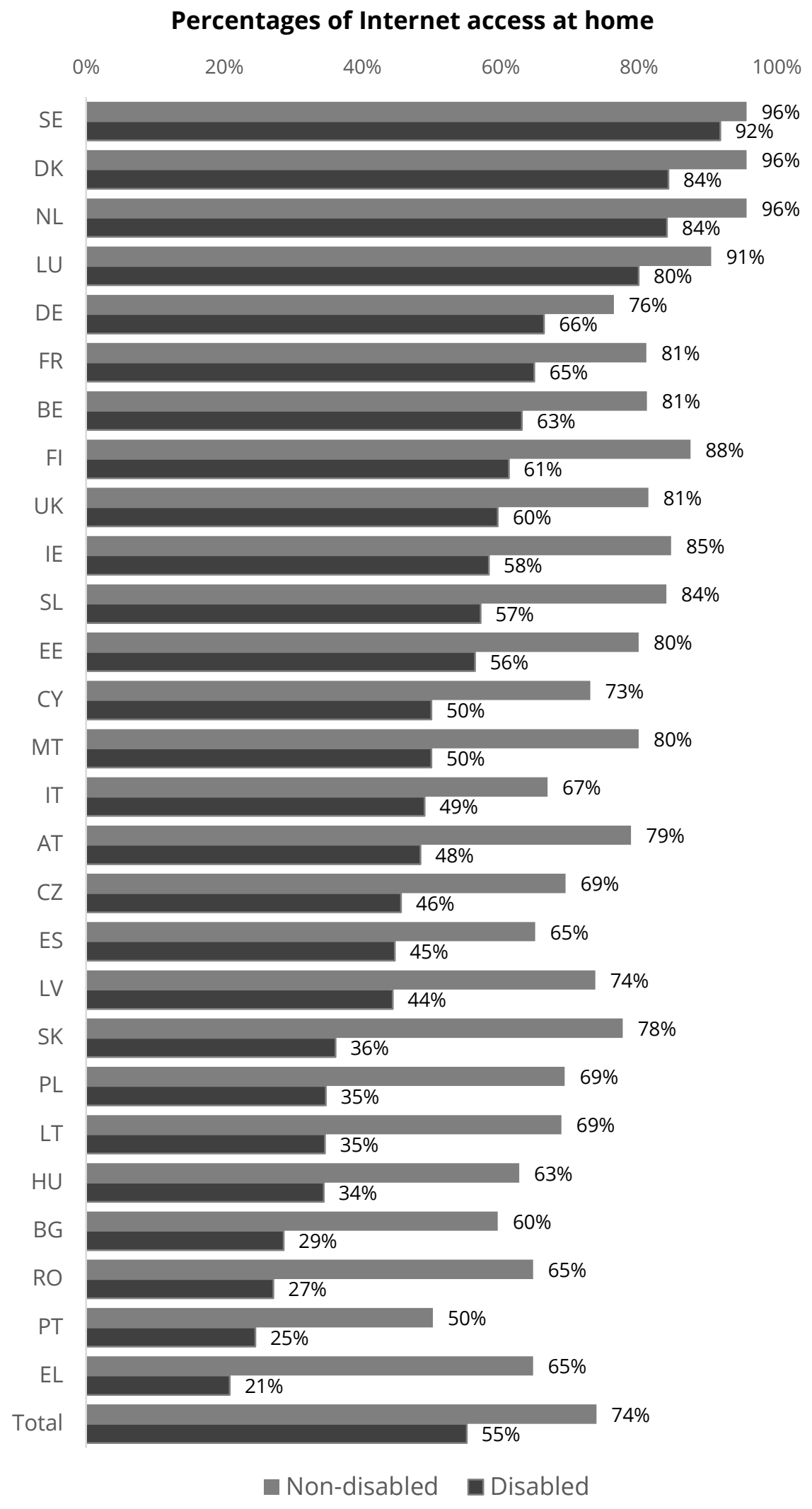

Figure 1. Internet access at home by disability status in EU27 countries (Eurobarometer 2012). 
Exploratory data analysis provides a broader perspective on the socio-demographic characteristics of the respondents (which feeds later into the multilevel logistic regression analysis). In general, across the sample aged 15 and above, there were more women than men (54\% female; $46 \%$ male) and approximately $60 \%$ were aged under 55. More than a third either had a tertiary education (29.9\%) or were still studying (7.5\%) and nearly two-thirds (62\%) reported their household financial situation as good. A significant proportion (28\%) reported that they lived alone. This social pattering reflects the relatively affluent but also ageing population of the EU. A summary of the descriptive statistics derived from Eurobarometer 2012 is shown in Table 1.

Table 1: Summary of Descriptive Statistics.

\begin{tabular}{lll}
\hline Factors & & $\%$ \\
\hline Internet access at home & Yes & 69.8 \\
Activity limitation (disability) & No & 30.2 \\
& Yes & 17.5 \\
Educational attainment level & No & 82.5 \\
& Low & 18.7 \\
& Middle & 44.0 \\
Household composition & High & 29.9 \\
& Still studying & 7.5 \\
& Single & 22.0 \\
Age cohort & Two & 33.4 \\
& Three & 18.5 \\
& Four + & 26.2 \\
& $15-24$ age band & 11.5 \\
& $25-34$ age band & 14.0 \\
Gender & $35-44$ age band & 16.7 \\
Financial situation & $45-54$ age band & 19.9 \\
& $55-64$ age band & 16.9 \\
\hline
\end{tabular}

Note: $N=26,622(\mathrm{~EB}, 2012)$

Chi-squared tests were used for bivariate analysis to explore the relationship between variable pairs. All of the selected factors yielded statistically significant effects on Internet access at home $(p<.001)$. In addition to the effect of disability status, men were slightly more likely to report access than women. Older people were much less likely to have Internet access at home than younger age groups (which might account also for some gender difference). The financial situation in the household also had a dramatic effect. People who reported a good household financial situation were much more likely to have Internet access at home than those who felt their situation was poor. Groups with higher levels of educational attainment, or still in education, reported higher levels of Internet access at home. Households including two or more people were more likely to have Internet access than single person households. These bivariate differences are shown in Table 2.

At the next step, multilevel logistic regression models were fitted to predict Internet access at home on the basis of disability status and the five other socio-demographic variables of interest, controlling for the country of residence. Five models were generated, from unconditional (M0) to a contextual model with cross-level interactions (M4). Given the limitations of space here, we discuss mainly the results for the complete contextual model.

The process begins with evaluation of the overall 'fit' of the model, to establish how helpful it is in explaining the results. A log likelihood ratio test of the contextual model, combining all the variables, helps to show whether this has a greater capacity to predict the likelihood of having Internet access at home than the effect of disability status on its own (the baseline model). The significance tests suggest that the contextual model explained more of the variance. In other words, the accuracy of the model improved when all the other socio-demographic 
factors were inserted into the equation. With the validity of the model confirmed, we proceed to discuss the effect of the variables. Table 3 shows the results gathered at each step of the analysis.

Table 2. Bivariate Analysis.

\begin{tabular}{|c|c|c|}
\hline \multirow[t]{2}{*}{ Factors } & \multicolumn{2}{|c|}{ Internet access } \\
\hline & No & Yes \\
\hline \multicolumn{3}{|c|}{ Self-declared activity limitation (disability status) } \\
\hline No & 26.4 & 73.6 \\
\hline \multirow[t]{2}{*}{ Yes } & 47.6 & 52.3 \\
\hline & $\chi^{2}=81$ & $f(1), p<.001$ \\
\hline \multicolumn{3}{|c|}{ Educational attainment level } \\
\hline Low & 63.9 & 36.1 \\
\hline Middle & 31.0 & 69.0 \\
\hline High & 13.1 & 86.9 \\
\hline \multirow[t]{2}{*}{ Still studying } & 7.2 & 92.8 \\
\hline & $\chi^{2}=423$ & $f(3), p<.001$ \\
\hline \multicolumn{3}{|c|}{ Household composition } \\
\hline Single & 52.5 & 47.5 \\
\hline Two & 36.9 & 63.1 \\
\hline Three & 16.7 & 83.3 \\
\hline \multirow[t]{2}{*}{ Four +} & 12.4 & 87.6 \\
\hline & $\chi^{2}=$ & $f(3), p<.001$ \\
\hline \multicolumn{3}{|l|}{ Age cohort } \\
\hline $15-24$ age band & 11.5 & 88.5 \\
\hline 25-34 age band & 13.6 & 86.6 \\
\hline 35-44 age band & 14.8 & 85.2 \\
\hline 45-54 age band & 22.5 & 77.5 \\
\hline 55-64 age band & 37.0 & 63.0 \\
\hline \multirow[t]{2}{*}{$65+$} & 62.0 & 38.0 \\
\hline & $\chi^{2}=464$ & $f(5), p<.001$ \\
\hline \multicolumn{3}{|l|}{ Gender } \\
\hline Female & 31.1 & 68.9 \\
\hline \multirow[t]{2}{*}{ Male } & 29.0 & 71.0 \\
\hline & $\chi^{2}=1$ & $f(1), p<.001$ \\
\hline \multicolumn{3}{|c|}{ Financial situation } \\
\hline Bad & 43.4 & 56.6 \\
\hline \multirow[t]{2}{*}{ Good } & 21.8 & 78.2 \\
\hline & $\chi^{2}=137$ & $f(1), p<.001$ \\
\hline
\end{tabular}

The chance of having Internet access at home was $62 \%$ lower for people who reported activity limitation (disability status) than for those who did not, but there were no significant gender effects when the other factors were controlled. The odds ratio of having Internet access at home decreased as the age cohort increased, especially for people aged 55 and older. For people aged 45-54, the chance of having Internet access at home decreased by $20 \%$ compared to people aged under 25 . For those aged 55-64 the reduction was $67 \%$. For the oldest age cohort, the odds ratio dropped further, meaning that people aged 65 or above had an $86 \%$ lower chance of having Internet access at home than the youngest age cohort.

As the level of educational attainment increased so did the likelihood of having Internet access at home. People who had completed tertiary education were twice as likely to have access as those who had not, and six times more likely than early school leavers. People who reported a positive household financial situation were also twice as likely to have Internet access at home as those who did not. 
Table 3. Results of the Multilevel Logistical Regression.

\begin{tabular}{|c|c|c|c|c|c|c|c|c|c|c|}
\hline \multirow[t]{2}{*}{ Characteristics } & \multicolumn{2}{|c|}{ MO } & \multicolumn{2}{|c|}{ M1 } & \multicolumn{2}{|c|}{ M2 } & \multicolumn{2}{|c|}{ M3 } & \multicolumn{2}{|c|}{ M4 } \\
\hline & $\begin{array}{c}\text { Co- } \\
\text { efficient }\end{array}$ & $\begin{array}{l}\text { Odds } \\
\text { ratio }\end{array}$ & $\begin{array}{c}\text { Co- } \\
\text { efficient }\end{array}$ & $\begin{array}{l}\text { Odds } \\
\text { ratio }\end{array}$ & $\begin{array}{c}\text { Co- } \\
\text { efficient }\end{array}$ & $\begin{array}{l}\text { Odds } \\
\text { Ratio }\end{array}$ & $\begin{array}{c}\text { Co- } \\
\text { efficient }\end{array}$ & $\begin{array}{l}\text { Odds } \\
\text { ratio }\end{array}$ & $\begin{array}{c}\text { Co- } \\
\text { efficient }\end{array}$ & $\begin{array}{l}\text { Odds } \\
\text { ratio }\end{array}$ \\
\hline Disability status & & & $\begin{array}{c}1.132 \\
\star \star \star\end{array}$ & $\begin{array}{l}.322 \\
* * *\end{array}$ & $\begin{array}{c}1.130 \\
* \star \star\end{array}$ & $\begin{array}{l}.322 \\
* * *\end{array}$ & $\begin{array}{c}-.312 \\
\star \star \star\end{array}$ & $\begin{array}{l}.731 \\
\star \star \star\end{array}$ & $\begin{array}{c}-.961 \\
\star \star \star\end{array}$ & $\begin{array}{l}.382 \\
* * *\end{array}$ \\
\hline \multicolumn{11}{|l|}{ Educational Attainment (ref Low) } \\
\hline Middle & & & & & & & $\begin{array}{l}.883 \\
\star \star *\end{array}$ & $\begin{array}{c}2.419 \\
\star \star \star\end{array}$ & $\begin{array}{l}.883 \\
\star * *\end{array}$ & $\begin{array}{c}2.420 \\
\star \star \star\end{array}$ \\
\hline High & & & & & & & $\begin{array}{c}1.895 \\
\star * *\end{array}$ & $\begin{array}{c}6.658 \\
\star \star *\end{array}$ & $\begin{array}{c}1.896 \\
\star \star \star\end{array}$ & $\begin{array}{c}6.665 \\
\star \star \star\end{array}$ \\
\hline Still studying & & & & & & & $\begin{array}{c}1.771 \\
\star * \star\end{array}$ & $\begin{array}{c}5.877 \\
\star * *\end{array}$ & $\begin{array}{c}1.776 \\
\star \star \star\end{array}$ & $\begin{array}{c}5.910 \\
\star \star \star\end{array}$ \\
\hline Household composition & & & & & & & $\begin{array}{l}.640 \\
\star \star \star\end{array}$ & $\begin{array}{c}1.896 \\
\star \star \star\end{array}$ & $\begin{array}{l}.594 \\
\star \star \star\end{array}$ & $\begin{array}{c}1.812 \\
\star \star \star\end{array}$ \\
\hline \multicolumn{11}{|l|}{ Age cohort (ref 15-24) } \\
\hline $25-34$ & & & & & & & .100 & 1.105 & .102 & 1.107 \\
\hline $35-44$ & & & & & & & .018 & 1.018 & .021 & 1.022 \\
\hline $45-54$ & & & & & & & $\begin{array}{c}-.207 \\
\star \star\end{array}$ & $\begin{array}{l}.812 \\
\star *\end{array}$ & $\begin{array}{c}-.221 \\
\star *\end{array}$ & $\begin{array}{c}.801 \\
\star *\end{array}$ \\
\hline $55-64$ & & & & & & & $\begin{array}{l}-.800 \\
\star \star \star\end{array}$ & $\begin{array}{l}.449 \\
\star \star \star\end{array}$ & $\begin{array}{l}-.830 \\
\star \star \star\end{array}$ & $\begin{array}{l}.435 \\
\star * \star\end{array}$ \\
\hline $65+$ & & & & & & & $\begin{array}{c}-1.899 \\
\star \star *\end{array}$ & $\begin{array}{l}.149 \\
* * \star\end{array}$ & $\begin{array}{c}-1.940 \\
* * *\end{array}$ & $\begin{array}{l}143 \\
* * *\end{array}$ \\
\hline Gender (ref Female) & & & & & & & .020 & 1.020 & .031 & 1.032 \\
\hline Financial Situation (ref Bad) & & & & & & & $\begin{array}{l}.727 \\
\star \star \star\end{array}$ & $\begin{array}{c}2.070 \\
\star \star \star\end{array}$ & $\begin{array}{l}.786 \\
\star * *\end{array}$ & $\begin{array}{c}2.196 \\
* * *\end{array}$ \\
\hline Disability*education & & & & & & & & & -.005 & 1.005 \\
\hline Disability*financial & & & & & & & & & $\begin{array}{l}-.330 \\
\star \star\end{array}$ & $\begin{array}{l}.718 \\
\star \star\end{array}$ \\
\hline Disability*gender & & & & & & & & & -.076 & .926 \\
\hline Disability*age & & & & & & & & & $\begin{array}{c}.061 \\
*\end{array}$ & $\begin{array}{c}1.063 \\
*\end{array}$ \\
\hline Disability*household & & & & & & & & & $\begin{array}{l}.275 \\
\star \star *\end{array}$ & $\begin{array}{c}1.316 \\
\star \star \star\end{array}$ \\
\hline Intercept & $\begin{array}{l}.941 \\
* * *\end{array}$ & $\begin{array}{c}2.564 \\
\star \star \star\end{array}$ & $\begin{array}{c}1.171 \\
* \star *\end{array}$ & $\begin{array}{c}3.228 \\
\star \star \star\end{array}$ & $\begin{array}{l}1.63 \\
\star \star \star\end{array}$ & 3.199 & $\begin{array}{c}-1.159 \\
\star \star \star\end{array}$ & $\begin{array}{l}.313 \\
\star * *\end{array}$ & $\begin{array}{c}-1.079 \\
\star \star \star\end{array}$ & $\begin{array}{l}.339 \\
\star \star \star\end{array}$ \\
\hline \multicolumn{11}{|l|}{ Random Effects } \\
\hline $\begin{array}{l}\text { Between Group Variance } \\
\text { var_cons[country] }\end{array}$ & .639 & & .700 & & .670 & & .825 & & .805 & \\
\hline $\begin{array}{l}\text { Slope Variance } \\
\text { var(disability[country) }\end{array}$ & & & & & .213 & & .159 & & .198 & \\
\hline $\begin{array}{l}\text { Covariance } \\
\text { cov(cons[country], }\end{array}$ & & & & & .436 & & -.216 & & .464 & \\
\hline Observations & 25,566 & 25,566 & 25,566 & 25,566 & 25,566 & 25,566 & 25,566 & 25,566 & 25,566 & 25,566 \\
\hline Number of Countries & 27 & 27 & 27 & 27 & 27 & 27 & 27 & 27 & 27 & 27 \\
\hline$-2 L L$ & & & $\begin{array}{l}947.98 \\
* \star \star\end{array}$ & & $\begin{array}{c}13.12 \\
* *\end{array}$ & & $\begin{array}{c}7677.39 \\
* \star\end{array}$ & & $\begin{array}{l}42.29 \\
\star \star *\end{array}$ & \\
\hline
\end{tabular}

Note: $N=26,622(\mathrm{~EB}, 2012){ }^{* \star *}$ Significance at .001 level ${ }^{* *}$ significance at .05 level ${ }^{*}$ significance at .10 level 
The household composition data introduced a notable effect. The ratio suggests that the likelihood of having Internet access at home increased by $81 \%$ for each unit increase in the number of people living in the household. Living with others has a strong positive linear relationship with the chance of having Internet access at home. However, the interaction of disability with these various social factors still needs to be considered.

Bearing this in mind, the next stage was to look at cross-level interactions between the disability effect and the effect of each socio-demographic variable. These interaction tests measure differences (between disabled and non-disabled people) in the rate of improvement in chances of Internet access that can be attributed to the other socio-demographic factors. For example, we know that a positive household financial situation improves the chances but does it do this more, or faster, for one group than the other? This is an important step towards untangling the relationships between different variables in the model and providing a basis for better understanding the disability digital divide in Europe.

Given the population demographic, and the patterning of activity limitation over the life course, some interaction of disability and age effects would be expected and this was evident from the model, although not at a high level of significance when controlling for other known factors. The chances of having Internet access at home did appear to decrease more rapidly at each age cohort step for people declaring activity limitations than for those who did not. There was no statistically significant gender effect when controlling for other factors (noting that Internet access here refers to the household, rather than individual women or men, there could be other gender inequalities of Internet usage within the home).

The interaction between disability and household financial situation revealed a more statistically significant effect $(p<.001)$. The odds ratio indicates that the anticipated increase in the chance of having Internet access at home, as a consequence of improved household finances, was $28 \%$ less for disabled people, compared to improvements in the chances for non-disabled people. Both groups gained more access from a good household financial situation but non-disabled people gained more. However, we did not find significant interaction evidence to show differences in the improved chances arising from higher educational attainment (disabled as well as non-disabled people gained rather more similarly in their chances of home Internet access from tertiary education, despite the fact that disabled people are less likely to attain this level of education).

The interaction of disability and household composition effects also showed a statistically significant difference $(p<.001)$. On average, a one unit change in the number of people living in the household increased the chance of having Internet access at home by $31 \%$ more for disabled people than it did for non-disabled people. Both disabled and non-disabled people benefitted from increased Internet access when they lived also with other people in the household and disabled people benefitted more.

These kinds of interaction effects do not necessarily reflect large differences in practice (both groups advance in a similar direction but they take smaller or larger steps). However, they do highlight the persistence of a disability effect on Internet access at home, which amplifies the already-known effect of socio-demographic influences. This scale of the overall disability effect on digital exclusion and its specific interactions with advancing age, poor household financial situation and living alone do merit attention.

\section{Discussion and Conclusion}

The aim of this study was to investigate the determinants of digital exclusion experienced by disabled people, focusing on basic Internet access at home and filling a gap in knowledge about the situation in Europe. It points the way for further research in this area and identifies new lines for enquiry. The availability of large scale empirical evidence has been somewhat patchy within the existing research literature on disability and the digital divide, but our findings are consistent with those of statistical analyses in the general field of digital exclusion. They also confirm and strengthen recent work on disability carried out in the USA and indicative EU studies or statistics, such as those cited earlier (Eurostat 2016a; Dobransky \& Hargittai 2016; Vincente \& Lopez 2010).

On average, seven out of ten European citizens had Internet access at home in 2012, but only five out of ten among those who declared an activity limitation connected to impairment or disability. Multilevel analysis confirmed that disabled people in the EU had a 62\% lower chance of having Internet access at home than non- 
disabled people. Alongside disability status, aging, low educational attainment, household finances and household composition also make a difference. The chances of having Internet access at home are reduced for people with only a basic education, those aged 45 and older, who live alone and/or have household financial constraints. In practice, the individual level socio-demographic factors evident from the general literature appear to explain most of the variance in Internet access at home but disability makes a difference too. Disabled people have a substantially lower chance of Internet access at home after controlling for other factors. In particular, the adverse effects of financial constraint, aging or living alone were significantly exacerbated for disabled people when compared to non-disabled people - the disability divide was wider in these respects.

Irrespective of disability status, age makes a difference, especially among the population aged 55 years and older. The Internet revolution is a relatively recent technological innovation and its social consequences have impacted more immediately on younger cohorts who have grown up with it throughout their education and employment careers. We might expect this cohort effect to lessen somewhat as time goes on, or to be replaced by new technology cohort effects. Nevertheless, it is vital to acknowledge that the majority of Europe's disabled population are in the older age groups and that this likelihood of disability compounds the digital exclusion associated with older age.

The significance of household financial situation (which in turn may be connected to educational attainment and employment chances) impacts on disabled people disproportionately. It is well established, throughout the world, that disability goes hand in hand with an increased risk of household poverty and that disabled people are disproportionately represented among the poorest of the poor. This is no less the case in the relatively wealthy countries of Europe. Disabled people, as well as older people, are more likely to have been early school leavers and they are less likely to be in employment. Exclusion from these domains, as well as the consequent financial hardship, may compound a lack of regular access to the Internet beyond the home as well as within it. Moreover, they may face additional disability-related costs of living that accentuate the exclusionary consequences of poverty (and these include the additional costs of specialist, non-standard or more accessible ICTs).

The disability gap in Internet access at home appeared to vary greatly between different countries in the EU, and in ways that cannot be explained easily by affluence or technological development. Some of this variance may be accounted for by differences in the prevalence of self-reported activity limitation (used in EU survey data as a proxy for disability status). There are some large differences, and notably among older age groups, which may be due to cultural, linguistic or policy conceptions of disability. However, there appears to be no clear association here either. The literature as well as the data suggests that levels of social exclusion play a part, notably in shaping prerequisite opportunities for adequate income and skills learning (e.g. Ragnedda \& Muschert, 2013). The disability literature also reminds us that access to these enablers, for disabled people, is strongly associated with differential levels of exclusion from mainstream education and from employment in European countries (e.g. Grammenos, 2015).

Some additional methodological limitations should be noted. The survey dataset was designed to evaluate discrimination in the EU political context (other Eurobarometer Survey Series do investigate Internet and ICT usage but they do not include questions that allow disaggregation of disability status). The structure of the survey questionnaire also limited the exploration of other factors that might have an effect on Internet usage (e.g. it was not possible to disaggregate ethnicity). The dummy variable created for Internet access at home does not distinguish work-related Internet usage from personal usage. Such limitations are not unusual in secondary analysis of existing surveys for disability research and the study also demonstrates how much more could be learned about these phenomena if disability questions were mainstreamed in all major EU surveys.

Further empirical research is needed to understand the discrepancies in outcome for disabled people between countries. This might help to explain how national policy differences, as well as family and household differences, affect Internet access for disabled people in Europe. For example, the extent to which inclusive educational opportunities, employment opportunities, the availability of disability benefits or supportive social services make a difference to ICT access and usage. 
This raises also the findings on household composition and, notably, the high risk of Internet exclusion among people who live alone ( $28 \%$ of all respondents reported that they did and $52 \%$ of them did not have Internet access at home). But this affects disabled people differentially. Living in a household with others has a significantly more positive impact on basic Internet access for disabled people than it does for non-disabled people. The interaction of disability and age compounds the overall household composition effect for disabled people in Europe, where younger adults are more likely to live in multi-person or family households and older people are more likely to live in two-person households or alone (particularly for women in the oldest age group). In this context, further consideration should be given to the digital access implications of supportive and informal learning relationships within the home.

While several other socio-demographic factors are significant in sustaining the digital divide there is a clear disability story, which is compounded by some these factors too. Policy interventions to lessen the digital equality gaps between disabled and non-disabled people are very welcome, and these include major steps in EU policy. The opportunities presented by the regulation of accessibility standards in the market for ICT goods and services will make a real difference for many disabled people and the prospect of a European Accessibility Act may hasten this process. However, it will make more of a difference if the minority who still remain excluded from the online revolution can be supported to access the Internet regularly from home. Disabled people are over-represented in this group. Both accessible technologies and appropriate supportive relationships are needed to address this unequal access.

\section{References}

Adam, A., \& Kreps, D. (2009). Disability and discourses of web accessibility. Information, Communication and Society, 12, 1041-1058. http://dx.doi.org/10.1080/13691180802552940

Bakardjieva, M. (2005). Internet society: The Internet in everyday life. London, Thousand Oaks, New Delphi: Sage.

Bargh, J. A., \& McKenna, K. Y. (2004). The Internet and social life. Annual Review of Psychology, 55, 573-590.

http://dx.doi.org/10.1146/annurev.psych.55.090902.141922

Cullen, R. (2003). The digital divide: A global and national call to action. The Electronic Library, 21, 313-334.

http://dx.doi.org/10.1108/02640470310480506

Dobransky, K., \& Hargittai, E. (2006). The disability divide in internet access and use. Information, Communication and Society. 9, 313-334. http://dx.doi.org/10.1080/13691180600751298

Disability Rights Commission (2004). The web: Access and inclusion for disabled people. London: TSO.

Easton, C. (2013). An examination of the Internet's development as a disabling environment in the context of the social model of disability and anti-discrimination legislation in the UK and USA. Universal Access in the Information Society, 12, 105-144.

EC. (2007). Assessment of the Status of eAccessibility in Europe. European Commission.

EC. (2008). Accessibility to ICT Products and services by Disabled and Elderly People. European Commission.

EC. (2010). European Disability Strategy 2010-2020: A Renewed Commitment to a Barrier-Free Europe. European Commission.

European Commission and European Parliament (2012). Eurobarometer 77.4 (2012). TNS OPINION \& SOCIAL, Brussels [Producer]. GESIS Data Archive, Cologne. ZA5613 Data file Version 3.0.0,

http://dx.doi.org/10.4232/1.12049

Eurostat (2016a). Internet access and use statistics - households and individuals (Online) Available at: http://ec.europa.eu/eurostat/statistics-explained/index.php/Internet_access_and_use_statistics__households_and_individuals

Eurostat (2016b). Disability statistics - prevalence and demographics. (Online) Available at:

http://ec.europa.eu/eurostat/statistics-explained/index.php/Disability_statistics___prevalence_and_demographics 
Goggin, G., \& Newell, C. (2000). An end to disabling policies? Towards enlightened universal service. The Information Society, 16, 127- 34.

Grammenos, S. (2015). European comparative data on Europe 2020 \& people with disabilities. Centre for European Social and Economic Policy (CESEP ASBL) on behalf of the Academic Network of European Disability Experts (ANED). Leeds/Utrecht

Greenfield, D., \& Davis, R. (2002). Lost in cyberspace: The web @ work. CyberPsychology \& Behavior, 5, 347-353.

Hargittai, E. (2001). Second-level digital divide: Mapping differences in people's online skills. arXiv preprint cS/0109068.

Norris, P. (2001). Digital divide: Civic engagement, information poverty, and the Internet worldwide. Cambridge University Press.

OECD (2001). Understanding the Digital Divide, OECD, Paris.

Oliver, M. (1990) The Politics of Disablement: A Sociological Approach, London: Palgrave Macmillan

Pilling, D., Barrett, P., \& Floyd, M. (2004). Disabled people and the Internet: experiences, barriers and opportunities. York, UK: Joseph Rowntree Foundation.

Ragnedda, M., \& Muschert, G. W. (Eds.) (2013). The digital divide: The Internet and social inequality in international perspective (Vol. 73). London and New York: Routledge.

Sevron, L. J. (2002). Bridging the digital divide: Technology, community and public policy. Malden, MA: Blackwell.

Van Deursen, A. J., \& Van Dijk, J. A. (2014). The digital divide shifts to differences in usage. New Media \& Society, 16, 507-526. http://dx.doi.org/10.1177/1461444813487959

Vincente, M. R., \& Lopez, A. J. (2010). A multidimensional analysis of the disability digital divide: Some evidence for Internet use. The Information Society, 26, 48-64. http://dx.doi.org/10.1080/01615440903423245

Wall, P. S. \& Sarver, L. (2003). Disabled student access in an era of technology. Internet and Higher Education, 6, 277-284. http://dx.doi.org/10.1016/S1096-7516(03)00046-0

Warschauer, M. (2004). Technology and social inclusion: Rethinking the digital divide. Cambridge and London: MIT press.

Wellman, B., \& Haythornthwaite, C. (Eds.). (2008). The Internet in everyday life. John Wiley \& Sons.

\section{Correspondence to:}

Frederike Scholz

Work and Employment Relations Division

Leeds University Business School

University of Leeds, LS29JT

England

Email: frederikescholz@gmail.com

Betul Yalcin

School of Sociology and Social Policy

Social Sciences Building

University of Leeds, LS29JT

England

Email: betulyn@gmail.com 


\section{About Authors}

Frederike Scholz is a current Postgraduate Researcher and Teaching Fellow in Human Resource Management at Leeds University Business School. Her PhD research focuses on disability inequality and the online recruitment process.

Betul Yalcin is a Senior Expert at the Ministry of Social Policy and Family Affairs (TR). She was recently awarded a PhD in Social Policy at the University of Leeds. Her PhD research is on active labour market policies for disabled people.

Mark Priestley is Professor of Disability Policy at the University of Leeds and Scientific Director of the European Commission's Academic Network of European Disability experts (ANED).

Editorial record: First submission received on September 11, 2016. Revision received on March 1, 2017. Accepted for publication on May 5, 2017. The article is part of Special Issue "Internet use and disability - Risks, opportunities and challenges" guest edited by Emma Sorbring and Martin Molin. 